\title{
Laboratory-based management of microbiological alerts: effects of an automated system on the surveillance and treatment of nosocomial infections in an oncology hospital
}

\author{
R Passerini ${ }^{1}$, R Biffi ${ }^{2}$, R Riggio ${ }^{1}$, S Pozzi ${ }^{2}$, MT Sandri ${ }^{1}$ \\ ${ }^{1}$ Laboratory Medicine Unit, European Institute of Oncology, Via Ripamonti 435, 20141, Milano, Italy \\ ${ }^{2}$ Abdomino-Pelvic Surgery Division, European Institute of Oncology, Milan, Italy
}

\begin{abstract}
Background: Prevention and surveillance programs are key to contain Nosocomial Infections (Nis). At the European Institute of Oncology, surveillance based on ex-post data collection has been done since the inception of hospital activity; laboratory-based surveillance of microbiological alert was not standardized. This study describes the issues related to the recent introduction into the hospital routine of a laboratory-based automated surveillance system and its clinical impact on monitoring and treatment of Nis.
\end{abstract}

Methods: An interdisciplinary team defined the alerts and the actions to be taken in response; recipients of the alert messages were identified and software was programmed. Program features were created so their employment would generate a prompt notification of clinically critical results. After a training period, the program was introduced in the hospital routine.

Results: There were a total of 150 generated alerts; the main alert related to microorganisms requiring prompt patient isolation and/or public notification. Clinical use of the program was relevant in detection and immediate notification of Cytomegalovirus active infection in stem cell recipients and central venous catheter related candidemia: the prompt administration of adequate treatment was possible hours earlier compared to the previous approach.

Conclusions: A laboratory-based automated surveillance system is effective in facilitating the management of Nis; its clinical employment also leads to important clinical advantages in patient care.

Published: 31/03/2009

Received: 01/03/2009

ecancer 2009, 3:137 DOI: 10.3332/ecancer.2009.137

Copyright: (c) the authors; licensee ecancermedicalscience. This is an Open Access article distributed under the terms of the Creative Commons Attribution License (http://creativecommons.org/licenses/by/2.0), which permits unrestricted use, distribution, and reproduction in any medium, provided the original work is properly cited.

Competing Interests: The authors have declared that no competing interests exist.

Correspondence to R Passerini. Email: rita.passerini@ieo.it 


\section{Introduction}

Nosocomial Infections (Nis) represent a great challenge for hospital personnel as a significant cause of increased mortality and morbidity in hospitalized patients, as well as increased costs of health-care systems; such that their rate is a recognized indicator of quality of care and safety $[1,2]$. Socialeconomic and human impact of Nis can be limited by implementing strict prevention actions and active surveillance programs [3]. Appropriate staff education, close adherence to guidelines and established procedures, in addition to continuous training, are the foundation of all effective preventive programs $[4,5]$.Currently, surveillance programs are based on the monitoring of clinically relevant infections through regular data collection and analysis, which allows the evaluation of local incidence of infections and their trends in comparison with retrospective data, as well as to identify outbreaks and risk factors and finally, to compare one's rates with the literature and/or other institutions' data. In addition to this periodical monitoring through time, a continuous and timely laboratorybased surveillance assures a prompt identification of sentinel events according to standard requirements [6-8]. The surveillance activity traditionally is performed through the manual review of computerized reports; this methodology however is labour-intensive and neither assures a sensitive detection of sentinel events/outbreaks nor a rapid intervention by infection control professionals; in fact, only the use of an automated system for Nis control, can provide an accurate and real-time surveillance at a lower cost $[9,10]$. Over the last few years, various electronic Nis surveillance systems have been developed which extract data from the database of microbiology laboratory, clinical wards, pharmacy and admission-transferdischarge and identify abnormal events and/or microorganism distribution compared to the standard procedure.

The aim of this article was to describe the issues regarding the implementation of a laboratory-based automated system, recently introduced in the hospital routine, which was able to identify microbiological alerts and to notify in real-time the involved professionals. We also analyse its clinical impact on the surveillance and treatment of Nis.

\section{Methods}

This study was prospectively carried out at the European Institute of Oncology (IEO) in Milan, a 226 inpatient-bed comprehensive cancer centre, operating since 1994 in cancer prevention, diagnosis, research and treatment. It includes two medical divisions (Medical Oncology and Haemato-Oncology), eight divisions of oncological surgery and a four-bed Intensive Care Unit (ICU).

At the time we implemented the automated system, the surveillance programs of major Nis had been continuously run at IEO by the application of standardized criteria, addressing: (i) category of infection to be monitored (ventilator-associated pneumonia, nosocomial pneumonia, central line-associated bloodstream infections, surgical site infections of selected surgical procedures and catheter-related urinary tract infections); (ii) data collection frequency (once a month); (iii) data collection sources (from microbiology laboratory reports, surgical wards and operating room databases, pharmacy and clinical records); (iv) data analysis and emission of reports by ICC (Infections Control Committee).

Our objective was to introduce a standardized method for microbiological alert surveillance and notification; thus in 2006, a computerized system for the identification of predefined sentinel events and their notification to clinicians, Chief Medical Office (CMO) and ICC members was implemented and introduced in the hospital routine.

The alert system developed initially involved the Microbiology Laboratory, Abdomino-Pelvic Surgery Division (APSD) and ICU. The software Virtuoso Plus ${ }^{\mathrm{TM}}$ (Metafora Informatica Srl, Milano, Italy) has been used, which was able to extract the data directly from the laboratory software and to elaborate the findings.

The early stage of the implementation of the new system was to identify sentinel events. An alert list, based on national and international scientific societies guidelines and recommendations [11], was determined by an interdisciplinary team who integrated these suggestions with IEO specific demands; thus in addition to universally accepted alerts (Methicillin-resistant Staphylococcus aureus (MRSA), Vancomycin-resistant Enterococci (VRE), multi-drug resistant $\boldsymbol{P}$. aeruginosa, etc), we added some events critical in our Institute, among which were, for example, Aspergillus species found in respiratory tract samples (IEO was in the progress of building renovation) [12-14]. To satisfy Nis control, according to the Centers for Diseases Control guidelines, ISS (Istituto Superiore di Sanità, corresponding to NIH-USA) and Regione Lombardia recommendations and IEO specific procedures, a list of actions to be taken in response to each event was issued, including what to do to contain the risk of transmission and how to proceed to notify the CMO and the local Healthcare Authority, when needed (Table 1).

Table 1: List of alerts and actions to be taken 


\begin{tabular}{|c|c|}
\hline ALERT & ACTION TO BE TAKEN \\
\hline Acinetobacter baumannii & $\begin{array}{l}\text { Contact precautions until the end of therapy and negative } \\
\text { culture }\end{array}$ \\
\hline Aspergillus species & Alert \\
\hline Mycobacteria in culture & $\begin{array}{l}\text { Notification to the } \mathrm{CMO}+\mathrm{ASL}+\text { possible airborne } \\
\text { precautions }\end{array}$ \\
\hline Mycobacteria by microscope & Notification to the $\mathrm{CMO}+\mathrm{ASL}+$ possible airborne \\
\hline & precautions \\
\hline $\begin{array}{l}\text { Strain ESBL (extended - spectrum beta - } \\
\text { lactamase) producing }\end{array}$ & $\begin{array}{l}\text { Contact precautions until the end of therapy and negative } \\
\text { culture }\end{array}$ \\
\hline Clostridium difficile (toxin $\mathrm{A}$ ) & Standard precautions until negative culture \\
\hline Enterococcus faecalis resistant to ampicillin & Alert \\
\hline VRE - Enterococci resistant to vancomicin & $\begin{array}{l}\text { Contact precautions until the end of therapy and negative } \\
\text { culture }\end{array}$ \\
\hline Hemophilus Influenzae resistant to ampicillin & Alert \\
\hline Urinary antigen Legionella positive & Notification to the $\mathrm{CMO}+\mathrm{ASL}$ \\
\hline Spinal fluid positive culture & $\begin{array}{l}\text { Notification to the } \mathrm{CMO}+\mathrm{ASL}+\text { possible airborne } \\
\text { precautions }\end{array}$ \\
\hline Listeria monocytogenes & Notification to the $\mathrm{CMO}+\mathrm{ASL}$ \\
\hline Neisseria gonorrhoeae & $\begin{array}{l}\text { Notification to the Medical Officer + possible } \\
\text { notification to ASL }\end{array}$ \\
\hline Pseudomonas aeruginosa multi- drug resistant & $\begin{array}{l}\text { Contact precautions until the end of therapy and negative } \\
\text { culture }\end{array}$ \\
\hline MRSA $-S$, aureus resistant to meticillin & $\begin{array}{l}\text { Contact precautions until the end of therapy and negative } \\
\text { culture }\end{array}$ \\
\hline VISA - S. aureus intermediate to vancomycin & $\begin{array}{l}\text { Contact precautions until the end of therapy and negative } \\
\text { culture }\end{array}$ \\
\hline VRSA - S. aureus resistant to vancomycin & $\begin{array}{l}\text { Contact precautions until the end of therapy and negative } \\
\text { culture }\end{array}$ \\
\hline $\begin{array}{l}\text { Streptococcus pneumoniae resistant to } \\
\text { cephalosporin }\end{array}$ & Alert \\
\hline $\begin{array}{c}\text { Streptococcus pneumoniae resistant to } \\
\text { penicillin }\end{array}$ & Alert \\
\hline Salmonella species in faeces & Notification to the $\mathrm{CMO}+\mathrm{ASL}+$ standard precautions \\
\hline Shigella species in faeces & Notification to the $\mathrm{CMO}+\mathrm{ASL}+$ standard precautions \\
\hline Stenotrophomonas maltophilia & $\begin{array}{l}\text { Contact precautions until the end of therapy and negative } \\
\text { culture }\end{array}$ \\
\hline Streptococcus not susceptible to vancomycin & Alert \\
\hline
\end{tabular}

Legend: CMO, Chief Medical Office; ASL, Azienda Sanitaria Locale (the local Healthcare Authority)

Table 2: Example of alerts extraction criteria with the software Virtuoso Plus 


\begin{tabular}{|c|c|c|c|}
\hline ALERT CODE & MRSA & CLOSTR & $\mathrm{MIC}$ \\
\hline $\begin{array}{c}\text { ALERT } \\
\text { DESCRIPTION }\end{array}$ & $\begin{array}{l}\text { Methicillin- } \\
\text { resistantStaphylococcus } \\
\text { aureus }\end{array}$ & $\begin{array}{c}\text { Clostridium difficile- } \\
\text { Toxin A }\end{array}$ & Fungi in blood culture \\
\hline $\begin{array}{l}\text { REFERENCE } \\
\text { DATE }\end{array}$ & Accession of sample & Accession of sample & Accession of sample \\
\hline $\begin{array}{l}\text { REQUEST } \\
\text { STATUS }\end{array}$ & Performed & Performed & Preliminary report \\
\hline $\begin{array}{c}\text { TAKE ONLY } \\
\text { PATIENT FIRST } \\
\text { EVENT }\end{array}$ & Yes & No & No \\
\hline $\begin{array}{l}\text { TAKE A NEW } \\
\text { EVENT IF } \\
\text { DIFFERENT } \\
\text { MATERIAL }\end{array}$ & No & Not applicable & Not applicable \\
\hline $\begin{array}{c}\text { ALERT } \\
\text { THRESHOLD }\end{array}$ & 1 & 1 & 1 \\
\hline $\begin{array}{l}\text { INVOLVED } \\
\text { DIVISIONS }\end{array}$ & All divisions & All divisions & All divisions \\
\hline $\begin{array}{c}\text { RECIPIENTS OF } \\
\text { ALERT } \\
\text { MESSAGE }\end{array}$ & $\begin{array}{c}\text { Chief of Microbiology } \\
\text { Laboratory,Directors and } \\
\text { Chief Nurses of involved } \\
\text { Divisions, ICC Operating } \\
\text { Group }\end{array}$ & $\begin{array}{c}\text { Chief of Microbiology } \\
\text { Laboratory, Directors and } \\
\text { Chief Nurses of involved } \\
\text { Divisions, ICC Operating } \\
\text { Group }\end{array}$ & $\begin{array}{c}\text { Chief of Microbiology } \\
\text { Laboratory,Directors and } \\
\text { Chief Nurses of involved } \\
\text { Divisions }\end{array}$ \\
\hline $\begin{array}{l}\text { EXTRACTION } \\
\text { TIMES } \\
\text { PLANNING }\end{array}$ & Once a day & Every 2 hours & Every 2 hours \\
\hline
\end{tabular}

Legend: ICC, Infections Control Committee.

Chief of Microbiology Laboratory, Epidemiology Nurse, Directors and Chief Nurses of the involved Divisions, CMO and ICC Operating Group were identified as recipients of the alert messages. The software setting proceeded: for each identified alert the extraction criteria were defined, including the strain of bacteria isolated, type of clinical sample, patients and divisions involved, recipients of messages and extraction time planning (Table 2).

A standardized alert message, containing a description of the alert event, patient's data, division of admission, sample examined and microbiological results, has been created to be automatically sent by email to the above recipients. At the same time, a list of all extracted alerts in the current session, with the indication of admission ward, was automatically generated and stored in a directory on the central server, available for evaluation by ICC members: this report allows the location of the contemporary presence of the same event in different patients, thus providing a tool to search for a common infection source (e.g. the same operating room or ICU stay). The extraction of alerts was planned once a day for the routine tests and every two hours for the tests needed urgently.

Due to the possibility of personalization, we resolved to also use this software for a prompt notification to the clinicians of clinically critical results, such as the growth of $\mathbf{S}$. aureus or Candida species in blood cultures or Cytomegalovirus and/or Herpes viruses genome detection in clinical samples after hematopoietic stem cell transplantation [15-17] among the others; we entered these alerts identifying, however, only the clinicians as message recipient. 
After a ten-month training period, involving only APSD and ICU, specifically dedicated to software validation and evaluation of technical functionality, we obtained a positive feedback of its employment and we decided to introduce this surveillance method in the hospital routine. To ensure its correct use by all operators, a new institutional procedure entitled 'Management of the Microbiological Alerts' was issued, and the program with its clinical relevance was presented to clinical directors and chief nurses (who in turn showed it to all the nursing staff); some posters to affix in each division, listing alerts and actions to be performed, were also distributed.

\section{Results}

From May 2006 to September 2008, 150 alert notifications were generated from samples sent to the laboratory for microbiological analysis. Table 3 shows these alerts with pertinent data and actions taken.

Multi-drug resistant $\boldsymbol{P}$. aeruginosa, S. maltophilia, extendedspectrum beta-lactamase (ESBL) and MRSA claimed the infected patients to be promptly placed in contact isolation in order to reduce the risk of direct or indirect transmission [18]. In particular, from January 2008 a significant increase of MRSA was detected, so, in addition to the isolation of patients, we planned some refresher courses on the isolation procedures for professionals, and a survey of our patients colonization at the time of admission and discharge. Mycobacteria and Salmonella related alerts led to both the isolation of patients and to public notification. With regard to the clinical employment of the program, $\boldsymbol{C}$. albicans strains were isolated from a central and a peripheral blood culture in two patients, with a Differential Time to Positivity $[19,20]$ proving a catheter-related bloodstream infection, thus forcing clinicians to immediately remove the device. The growths of $\boldsymbol{S}$. aureus in blood culture were not CVC-related. CMV genome found in three stem cell recipient patients led clinicians to start or change the antiviral therapy.

\section{Discussion}

At the IEO, since the beginning of hospital activity, an Infections Control Committee has ensured Nis surveillance through the review and approval of surveillance and prevention programs, the analysis of Nis collected data and identification of interventional areas, the assessment and promotion of better practices and staff training in infection control, the infectious risk assessment of new technologies and finally the communication and cooperation with external ICC for audit activities.
A rapid detection of microbiological alerts is also crucial for effective control of nosocomial outbreaks, of both common and unusual micro-organisms, and micro-organisms with unusual phenotypical traits (such as multi-drug resistance). Detection of these outbreaks by clinical evaluation is difficult, so it is usually found on periodic reports ex-post laboratory collected data, which is a fairly slow method and is late in outbreak detection.

A laboratory-based management of Nis control, on the contrary, allows the rapid survey of alerts; the electronic notification (by email) to the involved divisions ensures, on the other hand, a real-time receipt of the alert messages, thus facilitating the prompt accomplishment of actions required to find the cause, and the immediate implementation of effective measures to contain the risk and to treat infected patients. This was all accomplished following procedures and guidelines previously shared by all the staff. Only the use of an automated system made this surveillance method possible.

In the past, the survey of microbiological alerts at IEO was in the care of Microbiology Laboratory staff, without a standardized method; so, the implementation of an automated surveillance system is shown as a very positive choice, both for the standardization of alert extraction criteria and for the well-timed data reporting to clinicians, with evident advantages: in the case of infectious agents requiring the isolation of patients, for example, the reduction in time of alerts communication reduced the risk of patient-to-patient transmission of microorganisms. The immediate effect is a clinical advantage for the patients and the possibility for the hospital staff to monitor longitudinally the infectious epidemiological setting. The real-time communication of unusual data to division professionals and ICC members, moreover, ensures their continuous knowledge of the Nis current status. In the instances of infections requiring a public notification, this surveillance system allows an automated and documented-by email-notification of relevant data as requested by the Italian Health Care System, including patient anagraphical data, the isolated microorganisms, the date of the sampling and of the report, and finally the ward of admission.

In our experience, major advantages of this software are related to the capability to personalize the extraction criteria: with careful preliminary selection work, both the alerts and the notification's message recipients can be modified from time to time, according to the hospital needs. A major feature is the possibility of providing a message relevant for clinical use, allowing an immediate implementation of all needed therapeutic 
Table 3: Number of generated alerts and related clinical samples; in bold, clinically critical events

\begin{tabular}{|c|c|c|c|}
\hline ALERT & NUMBER & SAMPLE & ACTIONS TAKEN \\
\hline Mycobacteria & 23 & Respiratory tract & $\begin{array}{l}\text { Notification to the } \mathrm{CMO} \text { and } \\
\mathrm{ASL} \text {; airborne isolation }\end{array}$ \\
\hline ESBL strains & 18 & $\begin{array}{c}\text { Respiratory tract, surgical site, blood, } \\
\text { urine, pus }\end{array}$ & $\begin{array}{l}\text { Contact isolation until } \\
\text { the end of therapy and } \\
\text { culture negative }\end{array}$ \\
\hline MRSA & 32 & $\begin{array}{l}\text { CVC, respiratory tract, surgical site, } \\
\text { blood }\end{array}$ & $\begin{array}{l}\text { Contact isolation until } \\
\text { the end of therapy and } \\
\text { culture negative; staff } \\
\text { retraining; survey of all } \\
\text { patients colonization at } \\
\text { admission and discharge }\end{array}$ \\
\hline S. maltophilia & 13 & Respiratory tract, urine, drainage & $\begin{array}{l}\text { Contact isolation until } \\
\text { the end of therapy and } \\
\text { culture negative }\end{array}$ \\
\hline $\begin{array}{l}\text { P. aeruginosa multi - drug } \\
\text { resistant }\end{array}$ & 17 & $\begin{array}{c}\text { Respiratory tract, surgical site, urine, } \\
\text { drainage }\end{array}$ & $\begin{array}{l}\text { Contact isolation until } \\
\text { the end of therapy and } \\
\text { culture negative }\end{array}$ \\
\hline A. baumannii & 2 & Blood & $\begin{array}{l}\text { Contact isolation until } \\
\text { the end of therapy and } \\
\text { culture negative }\end{array}$ \\
\hline VRE & 2 & Surgical site & $\begin{array}{l}\text { Contact isolation until } \\
\text { the end of therapy and } \\
\text { culture negative }\end{array}$ \\
\hline Salmonella species in faeces & 1 & Faeces & $\begin{array}{c}\text { Notification to the CMO } \\
\text { and ASL; standard } \\
\text { isolation }\end{array}$ \\
\hline VISA & 1 & Surgical site & $\begin{array}{c}\text { Contact precautions until } \\
\text { the end of therapy and } \\
\text { culture negative }\end{array}$ \\
\hline VRSA & 1 & Respiratory tract & $\begin{array}{c}\text { Contact precautions until } \\
\text { the end of therapy and } \\
\text { culture negative }\end{array}$ \\
\hline$S$. aureus in blood culture & 20 & Blood & $\begin{array}{l}\text { Not CVC-related; } \\
\text { clinical procedure } \\
\text { standard }\end{array}$ \\
\hline Fungi in blood culture & 9 & Blood & $\begin{array}{l}\text { Removal of infected } \\
\text { device and } \\
\text { administration of } \\
\text { correct therapy }\end{array}$ \\
\hline CMV genome & $11(3 p t s)$ & Blood & $\begin{array}{l}\text { Reassessment of } \\
\text { antiviral therapy }\end{array}$ \\
\hline
\end{tabular}

Legend: CMO, Chief Medical Office; ASL, Azienda Sanitaria Locale (the local Healthcare Authority) 
actions and a real-time feedback of pertinent information in doubtful cases, so leading to important benefits in patient care: in the CVC-related candidemia, for example, clinicians, promptly alerted, could remove the device and start the correct therapy hours in advance compared to the previous approach, thus decreasing the risk of severe complications connected to this infection [21]; also the immediate signalling to clinicians of CMV genome detection in stem cell recipients allowed the adjustment of treatment without further delay [22].

Finally, the implementation of this system can lead to further results over time, not less significant than the clinical benefits already detected, but related to the educational value of this approach: regular and prompt notification of critical issues to all health-care staff will enhance their awareness for clinically relevant Nis, thus improving a safe environment.

\section{Acknowledgments}

We are grateful to the technician Lorena Moretti for her excellent laboratory assistance, to the chief nurses Cristina Simone and Liliana Tadini for their valuable collaboration and to Mara Jo Miller for her kind review of the manuscript. The authors declare that they have no actual or potential conflicts of interest. 


\section{References}

1. Leth RA and Moller JK (2006) Surveillance of hospitalacquired infections based on electronic hospital registries $\mathrm{J}$ Hosp Infect 62 71-9 PMID 16099539

2. Gastmeier P, Geffers C, Brandt C, Zuschneid I, Sohr D, Schwab $\mathrm{F}$ et al (2006) Effectiveness of a nationwide nosocomial infection surveillance system for reducing nosocomial infections $J$ Hosp Infect 64 16-22 PMID $\underline{16820247}$

3. Gordts B (2005) Models for the organisation of hospital infection control and prevention programmes Clin Microbiol Infect 11 (Suppl) S19-23 PMID 15760439

4. World Health Organization (2002) Prevention of hospitalacquired infections: A practical guide 2nd edn (Geneva: WHO)

5. Harbarth S, Sax H and Gastmeier P (2003) The preventable proportion of nosocomial infections: an overview of published reports J Hosp Infect 54 4 258-66 PMID 12919755

6. Canton R (2005) Role of the microbiology laboratory in infectious disease surveillance, alert and response Clin Microbiol Infect 11 (Suppl) S3-8 PMID 15816099

7. Kolmos HJ (2001) Role of the clinical microbiology laboratory in infection control - a Danish perspective $J$ Hosp Infect 48 (Suppl) S550-4 PMID 11759027

8. The Joint Commission (2006) Sentinel event policy and procedures - Update October 2006

9. Young $\mathrm{J}$ and Stevenson KB (2008) Real-time surveillance and decision support: optimizing infection control and antimicrobial choices at the poin of care $A m \mathrm{~J}$ Infect Control 36 (Suppl) S67-74

10. Hebden JN, Wright MO, Fuss EP and Standiford HC (2008) Leveraging surveillance technology to benefit the practice and profession of infection control $A m \mathrm{~J}$ Infect Control 36 (Suppl) S7-11

11. Garner JS (1996) RN, MN, and the Hospital Infection Control Practices Advisory Committee. Guidelines for isolation precautions in hospitals - Part II Infect Control Hosp Epidemiol 24 24-52

12. Mueller Bartley J APIC State-of-the-Art Report: The role of infection control during construction in health care facilities The 1997, 1998, and 1999 APIC Guidelines Committees

13. Morrison J, Yang C, Lin K-T, Haugland RA, Neely AN and Vesper SJ (2004) Monitoring Aspergillus species by quantitative PCR during construction of a multi-storey hospital building $\mathrm{J}$ Hosp Infect 57 85-7

14. Cooper EE, O'Reilly MA, Guest DI and Dharmage SC (2003) Influence of building construction work on Aspergillus infection in a hospital setting Infect Control Hosp Epidemiol 247 472-6 PMID 12887233

15. Wingard JR (1993) Infections in allogeneic bone marrow transplant recipients Semin Oncol 20 80-7 PMID 8211220

16. Boeckh M, Nichols WG, Papanicolaou G, Rubin R, Wingard JR and Zaia J (2003) Cytomegalovirus in hematopoietic stem cell transplant recipients: current status, known challenges, and future strategies Biol Blood Marrow Transplant 9 543-58 PMID 14506657

17. Zaia JA (2002) Prevention and management of CMVrelated problems after hematopoietic stem cell transplantation Bone Marrow Transplant 29 633-8 PMID $\underline{12180106}$

18. Garner JS (1996) RN, MN, and the Hospital Infection Control Practices Advisory Committee Guidelines for isolation precautions in hospitals - Part I Infect Control Hosp Epidemiol 17 53-80

19. Blot F, Nitenberg G, Chachaty E, Raynard B, Germann N, Antoun $S$ et al (1999) Diagnosis of catheter-related bacteraemia: prospective comparison of the time to positivity of hub-blood versus peripheral-blood cultures Lancet 354 1071-7 PMID 10509498

20. Raad I, Hanna HA, Alakech B, Chatzinikolaou I, Johnson MM and Tarrand J (2004) Differential time to positivity: a useful method for diagnosing catheter-related bloodstream infections Ann Intern Med 140 18-25 PMID 14706968

21. Hogevik H and Alestig K (1996) Fungal endocarditis-a report on seven cases and a brief review Infection 241 17-21 PMID 8852457

22. Ljungman $P$ (2002) Prevention and treatment of viral infections in stem cell transplant recipients $\mathrm{Br} J$ Haematol 118 44-57 PMID 12100127 